\title{
REVIEW
}

\section{The role of delta-like non-canonical Notch ligand 1 (DLK1) in cancer}

James F H Pittaway, Constantinos Lipsos, Katia Mariniello and Leonardo Guasti

Centre for Endocrinology, William Harvey Research Institute, Barts and the London School of Medicine and Dentistry, Queen Mary University of London, London, UK

Correspondence should be addressed to J F H Pittaway: jfhpittaway@doctors.org.uk

\begin{abstract}
Delta-like non-canonical Notch ligand 1 (DLK1) is a cleavable single-pass transmembrane protein and a member of the Notch/Delta/Serrate family. It is paternally expressed and belongs to a group of imprinted genes located on chromosome band 14q32 in humans and 12qF1 in mice. DLK1 is expressed in many human tissues during embryonic development but in adults expression is low and is mostly restricted to (neuro)endocrine tissues and other immature stem/progenitor cells (notably hepatoblasts). However, DLK1 is expressed at a high frequency in many common malignancies (liver, breast, brain, pancreas, colon and lung). More recently, high levels of expression have been identified in endocrine-related cancers such as ovarian and adrenocortical carcinoma. There is growing evidence that DLK1 expression in cancer is associated with worse prognosis and that DLK1 may be a marker of cancer stem cells. Although the exact mechanism through which DLK1 functions is not fully understood, it is known to maintain cells in an undifferentiated phenotype and has oncogenic properties. These effects are partly exacted through interaction with the Notch signalling pathway. In this review, we have detailed the functional role of DLK1 within physiology and malignancy and posited a mechanism for how it exacts its oncogenic effects. In describing the expression of DLK1 in cancer and in healthy tissue, we have highlighted the potential for its use both as a biomarker and as a potential therapeutic target.
\end{abstract} Key Words

\section{Introduction}

The first reported expression of the delta-like non-canonical Notch ligand 1 gene (DLK1) was in 1987. An investigation into differential expression of genes in the development of neuroendocrine tissues identified a cDNA clone termed ' $p G 2$ ' that had higher expression in phaeochromocytoma compared with neuroblastoma. It became referred to as 'human adrenal specific cDNA $p G 2$ ' as it was also shown to be highly expressed in both normal adrenal medulla and cortex (Helman et al. 1987).

Around the same time, the protein foetal antigen 1 (FA1) was isolated from normal human amniotic fluid in the second trimester of pregnancy (Fay et al. 1988). Analysis of the sequence of FA1 revealed that it was the translated product of the cDNA $p G 2$ (Jensen et al. 1993). FA1 was shown by immunohistochemistry to also be expressed in the foetal adrenal as well as the foetal liver and pancreas (Tornehave et al. 1989, 1993).

In 1993, a separate group identified a protein with differential expression in small cell lung cancer cell lines. Structural analysis of the protein revealed it was highly homologous with the proteins Delta, Serrate and Notch from Drosophila melanogaster and it was termed 'human (c) 2021 Society for Endocrinology Published by Bioscientifica Ltd. Printed in Great Britain 
Delta-like' (dlk) (Laborda et al. 1993). A further study of the structure of FA1 revealed 99\% alignment to human $d l k$ mRNA, with a 259 amino acid overlap, and that the cDNA sequences for $p G 2$ and $d l k$ were the same (Jensen et al. 1994). They identified that FA1 is synthesised as a membrane anchored protein that is released after enzymatic cleavage into the circulation.

In the same year, another group isolated a cDNA clone from the mouse preadipocyte cell line 3T3-L1, which was named 'preadipocyte factor 1' (Pref-1). Pref-1 was shown to inhibit the differentiation of adipocytes (Smas \& Sul 1993). The translated sequence of Pref- 1 protein was also found to be identical to that of mouse FA1 (Bachmann et al. 1996).

Thus, it was established that dlk, FA1, Pref- 1 and $p G 2$ are variant products of the same gene which is now most commonly referred to as delta-like non-canonical Notch ligand 1 (DLK1).

Taking these discoveries together, DLK1 was identified as a Notch family protein, expressed in foetal development, neuroendocrine cells and malignancies, with a role in inhibiting differentiation. These findings were informative in setting the scene for the further investigation of DLK1 and its proposed role in both physiology and disease.

\section{DLK1 structure}

The $D L K 1$ gene is paternally expressed and belongs to the DLK1-DIO3 gene cluster, a group of imprinted genes located on chromosome band 14q32 in humans and 12qF1 in mice (Gubina et al. 1999, 2000). It encodes a 383 amino acid, single-pass, transmembrane glycoprotein. The sequence and structure of DLK1 is like that of the canonical Notch ligand Delta-like 1 (DLL1) (Fig. 1A). DLK1 contains six EGF-like repeats, a juxtamembrane region with a cleavage site, a transmembrane domain and a small intracellular tail. Like other Notch ligands, the cleavage site of DLK1 is mediated through the action of the ADAM17 (a disintegrin and metalloprotease) also known as TNF $\alpha$ converting enzyme (TACE). Like DLL1, DLK1 contains the specialised tandem EGF repeats named the Delta/OSM-11 (DOS) domain. However, it lacks the N-terminal cryptic EGF-like repeat called the Delta-Serrate-LAG-2 (DSL) domain which is conserved in all canonical Notch ligands (Fig. 1A) (Smas \& Sul 1993, Scherer et al. 1995) and has been shown to be required for Notch trans-activation and cis-inhibition (Cordle et al. 2008).

Alternate spliced isoforms of DLK1 exist in different species. In mice, Dlk1 has six isoforms (Dlk1 A, B, C, C2, $\mathrm{D}, \mathrm{D} 2)$. Only Dlk1 A and B contain the juxtamembrane
A

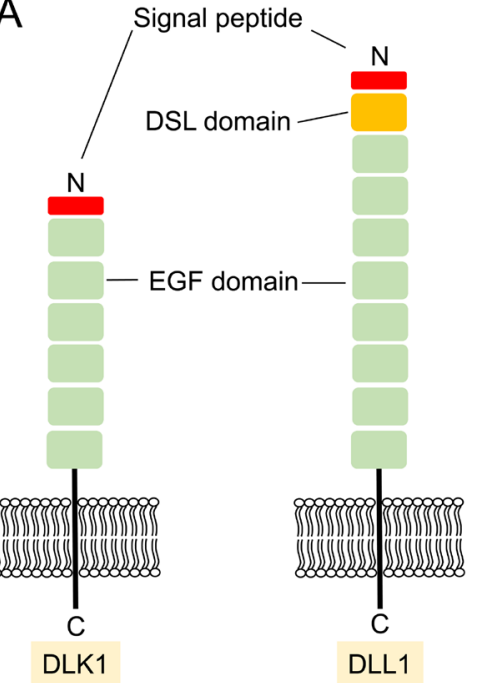

B

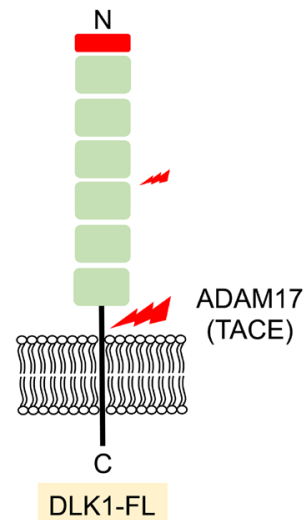

C
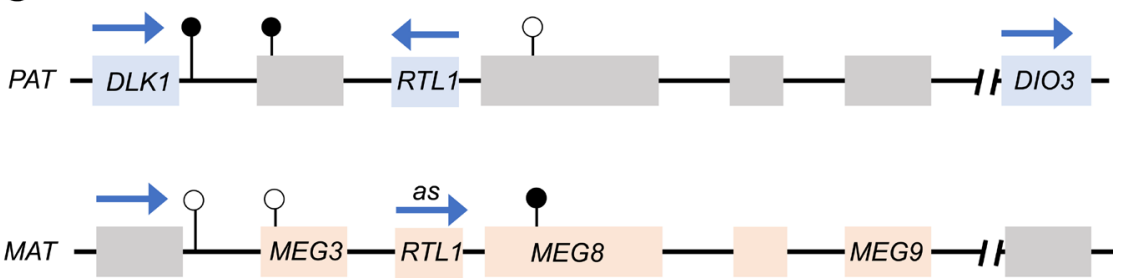

Figure 1

The structure of DLK1. (A) Diagram showing the similarity between the structure of DLK1 and canonical Notch ligand DLL. (B) Diagram of the two known human isoforms of DLK1, the full-length cleavable isoform (DLK1-FL) and the membrane-bound isoform (DLK1-MB). The large bolt identified the ADAM17-mediated juxtamembrane cleavage site for the full-length ligand. Smaller bolts identify the other protease cleavage site. (C) Diagram of the imprinted DLK1-DIO3 domain. Blue arrows indicate direction of transcription. Circles indicate imprinting control regions (ICR), filled circles, hypermethylated, empty circle, hypomethylated. PAT, paternal allele; MAT, maternal allele, as, antisense. A full colour version of this figure is available at https:// doi.org/10.1530/ERC-21-0208. 
ADAM17 cleavage site and can produce the full length 50 $\mathrm{kDa}$ soluble ligand. The other isoforms are thought to be tethered to the membrane. All isoforms contain another protease cleavage site within the fourth EGF-like repeat which leads to production of a $24-25 \mathrm{kDa}$ ligand thought to be biologically inactive. In humans, only two isoforms of DLK1 are recognised, one membrane tethered and one cleavable (Fig. 1B) (Smas \& Sul 1993, Mei et al. 2002).

Theexpression of $D L K 1$ is regulated byepigeneticprocesses within the DLK1-DIO3 imprinted domain. This domain contains three paternally expressed protein-coding genes $D L K 1$, retrotransposon gag-like 1 (RTL1) and iodothyronine deiodinase 3(DIO3). Additionally, it contains three maternally expressed long ncRNAs (lncRNAs) maternally expressed genes 3 and 8 (MEG3, MEG8) and an antisense transcript for RTL1. Numerous short ncRNA genes are also found in this domain. The paternal expression of DLK1 and maternal expression of $M E G 3$ is mainly regulated by imprinting control regions (ICR) which are differentially methylated regions (DMR) found between the two genes. These ICR are hypermethylated on the paternal allele and hypomethylated on the maternal allele (Fig. 1C) (Enterina et al. 2017). The ICR hypomethylation on the maternal allele leads to imprinting of $D L K 1$ as it allows the binding of transcriptional repression proteins that insulate $D L K 1$ from downstream enhancers. In the paternal allele, hypermethylation at this region prevents binding of the transcriptional repression protein, allowing DLK1 transcription and expression.

\section{DLK1 expression in physiology}

DLK1 is expressed in many human tissues during embryonic development but in adults expression is low and is mostly restricted to (neuro)endocrine tissues and other immature stem/progenitor cells.

\section{Endodermal tissues}

In the adult pancreas, DLK1 expression is restricted to a subset of insulin-producing $\beta$ cells in the islets of Langerhans. However, in the developing foetus, DLK1 positivity is seen in $94 \%$ of glandular epithelial cells at 7 weeks of gestation. This expression decreases throughout embryonic development and to a level of only $11 \%$ seen at 4 months after birth (Tornehave et al. 1993). Throughout development, DLK1 expression is not seen in other pancreatic endocrine cells and is negatively correlated with glucagon expression (Tornehave et al. 1996).

In the prostate, DLK1 is expressed in the basal layer of epithelial cells in the lumen. It is co-expressed with markers of stem cells and of intermediate cells in the development of differentiated luminal cells and other neuroendocrine subpopulations (Ceder et al. 2008).

\section{Mesodermal tissues}

This picture of higher DLK1 expression in tissues during early development, reducing through embryogenesis to be absent or only present in progenitor cells of a developed tissue, is investigated and described best in mesodermal tissues. In the developing human liver, a high level of DLK1 expression is seen in early gestation and this is reduced to about $6 \%$ in all liver cells by 20 weeks of gestation (Schmelzer 2019). DLK1 has shown to be a marker of hepatoblasts, the transient amplifying progenies of hepatic stem cells (Tanimizu et al. 2003). After birth and in adulthood, DLK1 expression is no longer present in differentiated hepatocytes (Tornehave et al. 1993). DLK1 is also seen in foetal lung acini but only after 17 weeks of gestation. Like the liver, DLK1 expression is not seen after birth (Floridon et al. 2000). In bone, DLK1 expression appears at 6 weeks of gestation and increases up to 13 weeks after which it declines. DLK1 expression in adult bone is only $10 \%$ of that seen at 13 weeks' gestation and is restricted to osteoblasts (Abdallah et al. 2004).

As described above, DLK1 is also known as preadipocyte factor 1 (Pref-1). Much of the investigation into Pref-1 has been conducted in mouse-derived cell lines and rodent models leading to some of the functional understanding of the protein which will be discussed later. DLK1 has been shown to identify a subpopulation of progenitor adipocyte cells that surround the small vessels in adipose tissue. This expression is markedly higher in s.c. than in visceral adipose tissue (Zwierzina etal. 2015). In the developing human foetus, foetal mesenchymal stem cells show a gradual increase in DLK1 expression during adipogenic differentiation until day 14 when expression decreases (Morganstein et al. 2010).

A similar pattern of DLK1 expression is seen in developing skeletal muscle. DLK1 expression is high in the muscle fibres of early gestational age embryos. Expression decreases throughout gestation and is absent in neonates and adults. DLK1 is also expressed in the precursor mononuclear cells adjacent to the muscle fibres. In these cells, expression remains at a constant level throughout development and is seen in neonates although not in adult muscle tissue (Andersen et al. 2009). Taken together, these expression data fit with a role for DLK1 in myogenesis.

The kidney is the one mesoderm-derived tissue where DLK1 expression is seen in differentiated cells during development. Epithelial cells of the proximal tubules express DLK1 during development and in adulthood (c) 2021 Society for Endocrinology Published by Bioscientifica Ltd. Printed in Great Britain 
(Floridon et al. 2000). Notably known progenitor cells of the kidney do not express DLK1 (Metsuyanim et al. 2009), suggesting possibly a different role for DLK1 in this tissue.

DLK1 expression in the adrenal gland has been established for over 30 years. The original identification of DLK1 was as a cDNA clone that was known as human adrenal specific cDNA pG2 (Helman et al. 1987). The description of $p G 2 / D L K 1$ in this context was notable as expression did not appear to be restricted by the lineage of the cell type and was found equally distributed in the mesoderm-derived adrenal cortex as well as the ectoderm-derived medulla. Work from our lab has detailed DLK1 expression in foetal adrenals throughout gestation and in adult adrenals throughout life. Cells expressing DLK1 remodel from a continuous subcapsular layer during development and childhood to form cell clusters in the third decade of life in physiologically normal human adrenals (Hadjidemetriou et al. 2019). These cells are relatively undifferentiated with expression data in keeping with a role for DLK1 as a marker of a precursor cell population. Contrary to its original description, DLK1 expression has been reported to be absent from adrenal medullary cells (Jensen et al. 1993); however, from our own unpublished work, we have seen that DLK1 is present in the human medulla but at lower levels compared to the cortex.

DLK1 expression in the gonads is similar to that seen in the adrenal cortex in keeping with their common developmental origin of the adrenal gonadal primordium. DLK1 expression is seen in interstitial Leydig cells of the developing testes. Expression is also seen in the adult testis in the same precursor Leydig cells. A similar pattern of DLK1 expression in described in the theca interna cells of the ovary. In post-menopausal women, DLK1 ovarian expression in restricted to lipid-rich vesicular cells (Jensen et al. 1999).

\section{Ectodermal tissues}

The expression of DLK1 in ectodermal tissues is not restricted to the adrenal medulla but it is also in the structures of the CNS. DLK1 expression is seen in both foetal and adult pituitary glands particularly but not exclusively in somatotroph cells (Larsen et al. 1996, Cheunsuchon et al. 2011). In addition to the pituitary, DLK1 is also expressed in the marginal and pseudostratified cells in the third ventricle in the foetal brain (Floridon et al. 2000). This expression is not seen in the adult brain where DLK1 expression is restricted to subsets of neurons in the pons and mesencephalon (Jensen et al. 2001).

\section{Summary}

The human expression data for DLK1 show a protein that is expressed in high levels in many tissue types during foetal development but is restricted to a few predominantly precursor cells mostly found in (neuro)endocrine tissues postnatally (Fig. 2). Based on these data alone it is possible to postulate a functional role for DLK1 in the growth and development of tissues. Similarly, the small cell populations found that express DLK1 in adulthood may regulate the self-renewal and homeostasis of these tissues.

\section{DLK1 expression in cancer}

It is becoming increasingly well recognised that dysregulation of pathways involved in the development and homeostasis of tissues is implicated in the pathogenesis of cancer. DLK1 expression in tissue development makes it an attractive protein for further investigation in cancer. Although postnatal DLK1 expression is restricted to progenitor cells in a few tissues, expression is observed at high frequency in many common malignancies (liver, breast, brain, pancreas, colon and lung) and other endocrine-related cancers (Table 1).

\section{Liver}

The expression of DLK1 in cancer is most well studied in the liver, where DLK1 is an accepted marker of hepatoblasts. Hepatoblastoma is a paediatric malignancy of the liver believed to be derived from hepatoblasts. DLK1 is expressed in up to $100 \%$ of hepatoblastomata studied. This has been shown previously at both protein and mRNA level (Luo et al. 2006, Dezsó et al. 2008).

Recently, a large pangenomic analysis of hepatoblastoma has revealed that upregulation of imprinted genes from the $14 \mathrm{q} 32$ locus, including $D L K 1$, is a genetic hallmark of the malignancy (Carrillo-Reixach et al. 2020). This study has proposed a novel molecular risk stratification for the malignancy and showed that DLK1 expression, although raised across the spectrum of disease, is significantly higher in the intermediate and higher molecular risk groups than in the lower risk. Higher gene expression from this locus is associated with nearby $\mathrm{CpG}$ hypomethylation suggestive that this is the epigenetic mechanism of the increased expression observed. The level of CpG hypomethylation at this locus is higher in hepatoblastoma than seen in normal liver tissue but lower than seen in foetal liver suggestive that in this malignancy there is a reversion to a tissue development phenotype. In keeping with this, the level of gene expression at $14 \mathrm{q} 32$ is correlated with increased expression of stem markers and activation of Wnt/ $\beta$-catenin signalling, a crucial pathway in tissue development and homeostasis. 


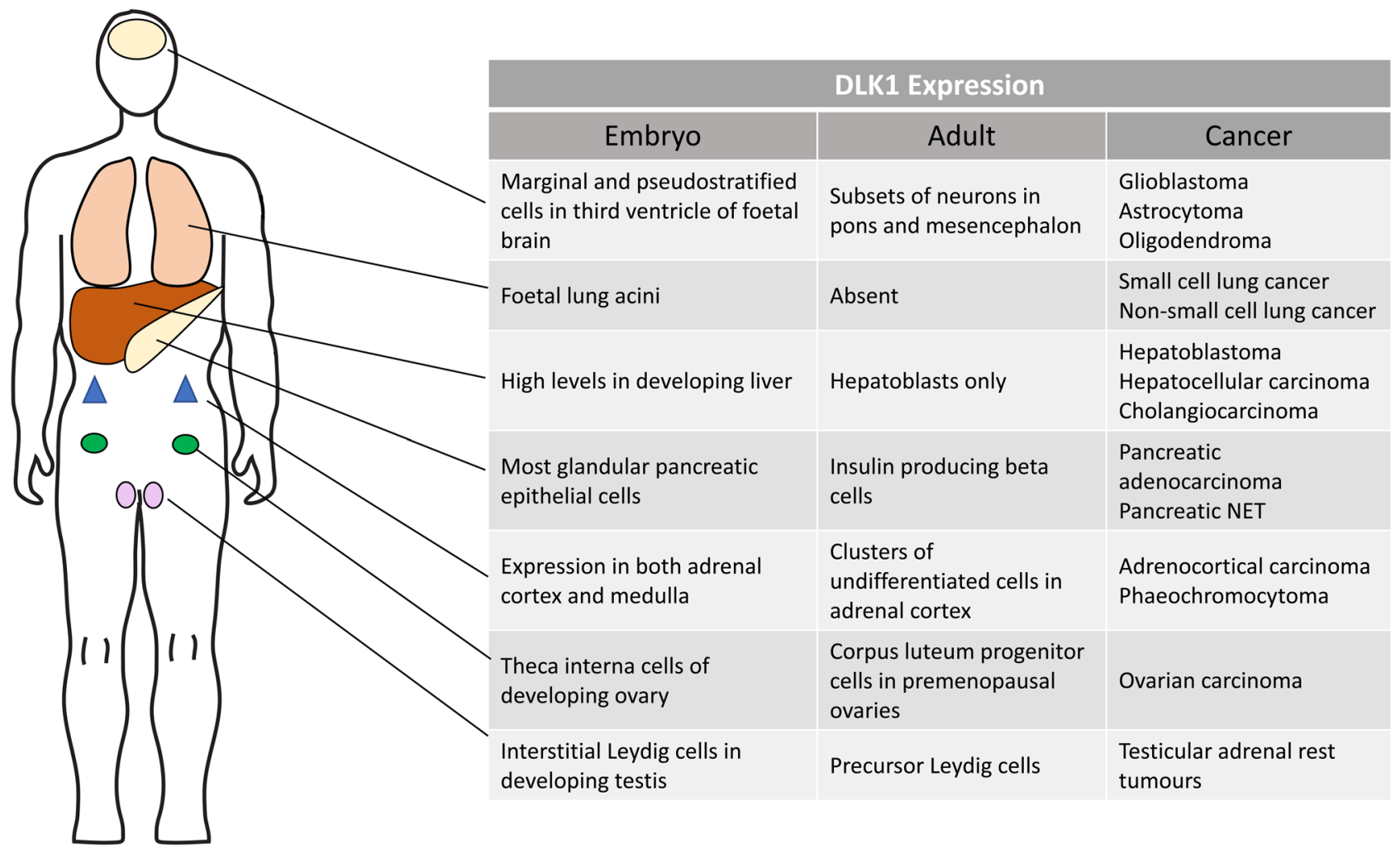

Figure 2

The expression of DLK1 in embryogenesis, physiology and cancer. Diagram illustrating the expression of DLK1 in selected human tissues during embryonic development, the restriction of expression to smaller subpopulations of precursor cells in adulthood and the re-expression seen in tumours and malignancies derived from these tissues. A full colour version of this figure is available at https://doi.org/10.1530/ERC-21-0208.

DLK1 expression is also a recognised feature of other liver malignancies. In hepatocellular carcinoma (HCC), DLK1 expression is reported at a variable frequency of 4-57\% at a protein level (Huang et al. 2007, Dezső et al. 2008, Yanai et al. 2010, Ikeda et al. 2013, Seino et al. 2018) (Table 1). In a recent study of the expression of hepatic progenitor cell markers in HCC and their effect on clinical outcome, DLK1 was expressed at the highest frequency of any marker assessed (16.7\%) (Seino et al. 2018). They also reported that the level of DLK1 expression was associated with worse recurrence free survival in univariate analysis. DLK1 expression was positively correlated with the expression of alpha-fetoprotein (AFP), an established biomarker of HCC, although some DLK1 positive tumours were AFP negative. This finding has been described previously and interestingly DLK1 expression has been shown to be a negative prognostic factor for overall survival in AFP negative liver malignancies (HCC, cholangiocarcinoma (CC) and mixed HCC/CC) (Jin et al. 2008). This study also found that DLK1 expression across these malignancies conferred worse overall survival compared to malignancies that were DLK1 negative.
It seems clear that DLK1 expression is a hallmark of hepatoblastoma and a subset of other differentiated liver malignancies. The variance in expression across the reported studies is likely to be explainable by different immunohistochemical criteria for positive expression and the sample sizes. DLK1 expression is associated with a worse prognosis, suggestive of a pathogenic role for DLK1 in cancer. Another study in HCC has shown that DLK1 is upregulated at an mRNA level in HCC compared to normal adjacent tissue at a high frequency (73\%) (Huang et al. 2007). This study also explored the epigenetic mechanism of increased DLK1 expression. Interestingly, they found that the increased expression of DLK1 was monoallelic and therefore not caused by loss of imprinting from the maternal allele. It suggested that the increased expression was likely a result of hypermethylation of the ICR or hypomethylation of other adjacent CpGs. They also reported DLK1 expression in a large number of AFP negative tumours (33/88). Taken together, the evidence of DLK1 expression in liver cancer is suggestive of a pathogenic role but also raises the possibility for the use of DLK1 as a biomarker in this field. 
Table 1 The expression of DLK1 in cancer

Tumour
Endocrine and neuroendocrine

Adrenocortical carcinoma

Medullary thyroid carcinoma

Ovarian

Pancreatic islet cell carcinoma

Carcinoid lung

Gastrointestinal carcinoid

Phaeochromocytoma

Paraganglioma

Testicular adrenal rest tumour

Somatotroph pituitary tumours

Lactotroph pituitary tumours

\section{Gastro-intestinal}

Pancreas adenocarcinoma

Colon adenocarcinoma

Gastric carcinoma

Gastro-intestinal stromal tumour

\section{Liver}

Hepatoblastoma

Hepatocellular carcinoma

Hepatocellular/cholangiocarcinoma Hepatocellular - cholangiocarcinoma Intrahepatic cholangiocarcinoma

\section{Lung}

Non-small cell lung cancer

\begin{tabular}{l}
\hline Paper \\
\hline (Hadjidemetriou \\
$\quad$ et al. 2019) \\
(Hadjidemetriou \\
$\quad$ et al. 2019) \\
(Turányi et al. 2009) \\
(Araujo et al. 2021) \\
(Turányi et al. 2009) \\
(Huang et al. 2019a)
\end{tabular}

\section{Renal}

Wilm's tumour

Renal cell carcinoma
(Yanai et al. 2010)

(Jensen et al. 1994)

(Turányi et al. 2009)

(Turányi et al. 2009)

(Turányi et al. 2009)

(Lottrup et al. 2014)

(Altenberger

et al. 2006)

(Altenberger

et al. 2006)

(Yanai et al. 2010)

(Yanai et al. 2010)

(Yanai et al. 2010)

(Xu et al. 2016)

(Dezső et al. 2008)

(Seino et al. 2018)

(Ikeda et al. 2013)

(Yanai et al. 2010)

(Dezső et al. 2008)

(Huang et al. 2007)

(jin et al. 2008)

(Ikeda et al. 2013)

(Ikeda et al. 2013)

(Liu et al. 2010)

(Takagi et al. 2021)

(Yanai et al. 2010)

(Tan et al. 2019)

(Takagi et al. 2021)

(Yanai et al. 2010)

(Jensen et al. 1994)

Expression

Protein IHC

Protein

lysate

Protein IHC

Protein IHC

Protein IHC

Protein IHC

Protein IHC

Protein IHC

Protein IHC

Protein IHC

Protein IHC

Protein IHC

mRNA

mRNA

Protein IHC

Protein IHC

Protein IHC

Protein IHC

Protein IHC

Protein IHC

Protein IHC

Protein IHC

Protein IHC

mRNA

Protein IHC

Protein IHC

Protein IHC

mRNA

Protein IHC

Protein IHC

Protein IHC

(Fukuzawa

et al. 2005)

(Fukuzawa

et al. 2005)

(Kawakami et al. 2006)

Protein IHC

Protein IHC

Protein IHC

Protein IHC

mRNA

Protein IHC
Protein IHC

\begin{tabular}{crr}
\hline Frequency & & Cases \\
\cline { 1 - 1 } $100 \%$ & & 9 \\
$100 \%$ & & 5 \\
& & \\
$100 \%$ & & 5 \\
$93 \%$ & & 27 \\
$45 \%$ & & 11 \\
$67 \%$ & & 221
\end{tabular}

Larger tumours

Advanced disease stages and LN metastases HGSC - worse OS and PFS

$\begin{array}{rr}50 \% & 6 \\ 83 \% & 6 \\ 10 \% & 20 \\ 100 \% & 13 \\ 100 \% & 4 \\ 100 \% & 8 \\ 100 \% & 5 \\ 50 \% & 2\end{array}$

$28 \%$

$59 \%$

$3 \%$

$37 \%$

$$
46
$$

58

30

412

$100 \%$

$19 \%$

$11 \%$

$21 \%$

$4 \%$

$57 \%$

$73 \%$

$37 \%$

$44 \%$

$13 \%$

$37 \%$

$17 \%$

$9 \%$

$75 \%$

$21 \%$

$53 \%$

$75 \%$

112

40

$43 \%$

30

$23 \%$

30

$22 \%$

50
Higher risk disease, larger tumours, worse OS and PFS

31

251

386

24

88

82

60

36

23

30

101

56

351

SCC - worse prognosis, advanced disease stages, LN metastases

Nuclear expression with NCOR1 - smaller tumours 
Table 1 Continued

\begin{tabular}{l}
\hline Tumour \\
\hline Sarcoma \\
Rhabdomyosarcoma \\
Liposarcoma \\
Brain \\
Astrocytomas \\
Glioblastoma \\
Oligodendrogliomas \\
Breast \\
Breast carcinoma \\
Blood \\
Acute myeloid leukaemia
\end{tabular}

\begin{tabular}{|c|}
\hline Paper \\
\hline $\begin{array}{l}\text { (Jørgensen et al. } \\
\text { 2013) } \\
\text { (Jørgensen et al. } \\
\text { 2013) }\end{array}$ \\
\hline $\begin{array}{l}\text { (Yin et al. 2006) } \\
\text { (Yin et al. 2006) } \\
\text { (Yin et al. 2006) }\end{array}$ \\
\hline (Yanai et al. 2010) \\
\hline (Khoury et al. 2010) \\
\hline
\end{tabular}

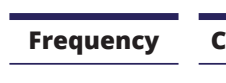

Protein IHC

Protein IHC

$76 \%$

$26 \%$

mRNA

mRNA

mRNA

Protein IHC

mRNA
Cases

Prognostic relevance of DLK1

17

19

13

31

7

59

This table details the expression of DLK1 across different cancers and relevant benign tumours. The frequency relates to the number of tumours within each cohort studied that express DLK1.

HGSC, high grade serous carcinoma; IHC, immunohistochemistry; OS, overall survival; PFS, progression-free survival; RFS, recurrence-free survival; SCC, squamous cell carcinoma.

\section{Lung}

DLK1 expression is also seen in lung cancer at a high frequency. This is seen in non-small cell lung cancer (NSCLC) (9-75\%), in neuroendocrine lung tumours including small cell lung cancer (SCLC) (21-75\%) and in carcinoid tumours (83\%) (Table 1). In NSCLC, DLK1 mRNA has been shown to be overexpressed in tumours compared with adjacent normal lung tissue in $37 \%$ of cases studied (Liu et al. 2010). The epigenetic mechanism behind this is not clearly understood but more recent work has shown that hypomethylation of the DLK1-DIO3 domain is a feature of NSCLC (Molina-Pinelo et al. 2018). This would implicate the role of CpG hypomethylation in DLK1 expression rather than ICR hypermethylation as described in liver cancer above and highlights the complex epigenetic regulatory mechanisms of gene expression at this imprinted cluster.

More recently, a larger study has reported DLK1 expression at a frequency of $20.5 \%$ of NSCLC and $17 \%$ of SCLC (Takagi et al. 2021). This study also reported a negative prognostic effect of DLK1 in NSCLC as DLK1 positive tumours conferred worse recurrence-free survival and was associated with a higher incidence of lymph node metastases. Like in liver cancer, there is a wide range of reported frequencies of DLK1 expression in lung cancer, but it would seem as it is present in a subset of tumours and that it may have a pathogenic role.

The role that DLK1 plays in NSCLC may be influenced by where the expression is reported within the cell. In a study from 2019, DLK1 expression in NSCLC was reported in a substantially higher frequency of cases than other reports (72.4\% of squamous cell carcinoma (SCC) and $77.4 \%$ of adenocarcinoma (ADC)) (Tan et al. 2019). This variance again

(c) 2021 Society for Endocrinology Published by Bioscientifica Ltd. Printed in Great Britain is likely explainable by immunohistochemical criteria used. For SCCs in this cohort, DLK1 expression had a negative prognostic role and was associated with advanced stages, positive node metastases and poor cell differentiation. However, the prognostic implication of DLK1 expression was influenced by the cellular location in which it was observed. In this cohort, nuclear DLK1 expression was reported in $30.5 \%$ of NSCLC tumour samples. In a small subset of patients, nuclear DLK1 was found to be co-expressed with nuclear receptor corepressor 1 (NCOR1), a known tumour suppressor, and in patients who generally had presented at an earlier disease stage. The DLK1 fragment observed at the nucleus was studied and found to be $30 \mathrm{kDa}$, smaller than the cleaved DLK1 ligand. It was postulated whether this might represent a fragment from the intracellular portion of the protein or a product of endocytosis from the ligand from other cells. The different implicated roles of the soluble vs membrane tethered isoforms of DLK1 in physiology and cancer are discussed below.

\section{Endocrine and neuroendocrine tumours}

The original identification of DLK1 as human adrenal specific $p G 2$ was made as it was a clone enriched in phaeochromocytoma vs neuroblastoma (Helman et al. 1987). Subsequentimmunohistochemicalanalyses reported DLK1 expression in 100\% of all phaeochromocytomata studied (Table 1). To our knowledge, further investigation of DLK1 in phaeochromocytoma is yet to be reported but would be informative to those working in this field. Our group and another have reported DLK1 expression as a ubiquitous feature of adrenocortical carcinoma (ACC) (100\% of cases studied) (Turányi et al. 2009, Hadjidemetriou 
et al. 2019). We have shown this at protein level both with immunohistochemistry and in tumour lysates. Additionally, analysis of The Cancer Genome Atlas (TCGA) and Genotype-Tissue Expression (GTEx) data show a fivefold upregulation of DLK1 transcripts in ACC compared to normal adrenal tissue (Hadjidemetriou et al. 2019). This upregulation of DLK1 in the malignancy of a tissue where it is expressed at low levels in normal physiology is analogous to the picture seen in liver cancer with hepatoblastoma and are important expression data for implicating a pathogenic role for DLK1 in these malignancies. Unpublished work from our lab has also identified that higher DLK1 expression is associated with worse recurrence-free survival in ACC.

Another endocrine malignancy with a reported pathogenic role for DLK1 is ovarian cancer. In a cohort of 221 ovarian carcinoma samples, encompassing all types of disease, DLK1 expression was high in $63.1 \%$ of cases (Huang et al. 2019a). Higher DLK1 expression is predictive of the presence of lymph node metastases and advanced stages of disease in univariate analysis in all types of ovarian carcinoma. Further to this, in high grade serous carcinoma (HGSC), DLK1 expression is related to worse overall and progression free survival and is an independent prognostic marker in this malignancy. They also reported that DLK1 expression is associated with an epithelial to mesenchymal transition (EMT) phenotype (reduced E-cadherin and increased vimentin expression). There is a suggestion that expression of mesenchymal markers in epithelial cancers confers a negative prognosis. This has been shown recently, where the mesenchymal marker SLUG is associated with a more aggressive disease phenotype in ACC, although there was no evidence of EMT seen in this study (Sbiera et al. 2021). The relationship between DLK1 and mesenchymal expression in ACC is yet to be studied.

DLK1 expression is reported in medullary thyroid carcinoma (MTC) at a high frequency (45 and 93\%) (Turányi et al. 2009, Araujo et al. 2021). The latter and most recent of these studies identified DLK1 in an unsupervised analysis of copy number alteration in MTC (Araujo et al. 2021). Copy number gain of $D L K 1$ was a common finding and strongly correlated with DLK1 protein expression. Higher copy number gain $(>2)$ of $D L K 1$ was associated with bigger tumours.

DLK1 expression has also been reported in pancreatic and gastrointestinal neuroendocrine tumours (NET) (38-50\% and 10\%, respectively), somatotroph pituitary tumours (100\%) and testicular adrenal rest tumours (TART) (100\%) where it can be used as an immunohistochemical marker to differentiate TART from Leydig cell tumours (Lottrup et al. 2014) (Table 1).

(c) 2021 Society for Endocrinology Published by Bioscientifica Ltd. Printed in Great Britain

\section{Mesenchymal tumours}

Gastrointestinal stromal tumours (GIST) are the most common mesenchymal tumours of the gastrointestinal (GI) tract. In the GI tract of healthy adults, there is very little to no DLK1 expression. A large study of 412 GISTs to ascertain potential drivers of malignancy has identified DLK1 mRNA expression in $37 \%$ of the tumours (Xu et al. 2016). In GISTs, DLK1 expression is associated with a higher risk disease, larger tumours with worse overall and progression-free survival. Multivariate analysis also identified DLK1 expression as an independent predictor of recurrence. Interestingly, DLK1 expression was predictive of treatment response. Improved disease-free survival was seen with adjunctive treatment with imatinib mesylate in DLK1 negative but not positive tumours. This is more convincing evidence of the pathogenic role of DLK1 within cancer and highlights another setting where it may have potential as a prognostic biomarker.

DLK1 is also expressed in other mesenchymal tumours. This is most clearly defined in rhabdomyosarcoma where DLK1 expression is reported at a high frequency (76\%) across the different subtypes (Jørgensen et al. 2013). This study found DLK1 expression to be much lower in liposarcoma (26\%) and not evident in osteosarcoma at a protein level on immunohistochemistry. More recently, DLK1 expression has been recognised at an mRNA level in osteosarcoma where it is upregulated compared to levels in adjacent healthy bone (Zhang et al. 2018). DLK1 mRNA expression was positively correlated with expression of the lncRNA DLX6-AS1 and negatively correlated with miR-129a-5p, another IncRNA known to target DLK1. Higher DLX6-AS1 levels are shown to be associated with worse prognosis. This again is suggestive of a functional role for DLK1 in this malignancy.

\section{Blood}

DLK1 mRNA has been shown to be upregulated in mononuclear bone marrow cells in patients with myelodysplastic syndrome compared to healthy controls (Ma et al. 2012). Interestingly, they reported that in acute myeloid leukaemia (AML), DLK1 levels are lower than the healthy controls; however, upregulation of $D L K 1$ in some cases of AML has been reported previously (Sakajiri et al. 2005). MDS and AML are both characterised by reduced terminal differentiation of cells, but in AML there is also unrestricted proliferation of these cells. These expression data suggest that in this malignancy, DLK1 has a predominant role in preventing terminal differentiation more so than proliferation.

Another study in AML has shown that DLK1 expression is increased in $61 \%$ of cases in their cohort. Interestingly, 
they have shown that in $76 \%$ of these cases, DLK1 expression is biallelic demonstrating a loss of imprinting (LOI) and implicating a CpG 18kb upstream from DLK1 as a likely insulator and transcription regulator binding site (Khoury et al. 2010). This evidence of loss of imprinting leading to increased expression of $D L K 1$ in AML is notable as LOI has not been found in the other malignancies with known DLK1 expression described above.

\section{Kidney}

LOI is implicated in the pathogenesis of many cancers but particularly in Wilm's tumours (the most common renal tumours to affect children). These tumours are associated with increased expression of insulin-like growth factor 2 (IGF2), another paternally expressed gene, and this is caused by LOI. Due to the expression, imprinting similarities between the IGF2/H19 and the DLK1/MEG3 domain DLK1 expression has also been studied in Wilm's tumours (Fukuzawa et al. 2005). DLK1 expression was seen at a protein level in $43 \%$ of tumours but this was not caused by LOI, even in tumours with known LOI of IGF2 that overexpressed DLK1. This is important as it shows that DLK1 expression in this and other malignancies with LOI cannot be attributed to a disruption of a shared imprinting mechanism.

DLK1 expression in the kidney is unique in physiology as it is the only mesodermally derived tissue where DLK1 is expressed in differentiated cells of the adult human. Apart from Wilm's tumours, DLK1 expression is also reported in renal cell carcinoma (RCC). A study looking into this showed that DLK1 expression was present in every normal kidney examined and that expression 'was lost' in 39/50 RCC examined (Kawakami et al. 2006). These expression data for the kidney do suggest that the role of DLK1 both in physiology and in malignancy may be different in this tissue from others.

\section{DLK1 function}

From the expression data of DLK1 in normal physiology and in cancer, it is possible to build up a picture of the implicated role of DLK1 in both processes. Overall, DLK1 is expressed at high levels throughout embryonic growth in many tissues and then restricted to a few populations of progenitor cells in adult life (Fig. 2). This pattern of expression is very much important in keeping with a role for DLK1 in somatic growth, tissue development and possibly tissue renewal. Furthermore, the upregulation of DLK1 across a wide range of malignancies suggests a reversion to a de-differentiated cell type which may display disordered cell cycle characteristics allowing for uncontrolled proliferation. The fact that in many malignancies, higher DLK1 expression within the cancer tissue confers negative prognostic outcomes is suggestive that DLK1 has an active role in the malignancy of many of these tumours. It is plausible that the functional role of DLK1 in physiology and in malignancy has not changed but that its functional effects in the context of cancer are important to the malignant potential of tumours. To understand better what the function of DLK1 is, we need to draw on collated evidence from rodent models and cell lines, both embryonic and malignant.

\section{Evidence from animal models and cell lines}

Evidence for the functional role of DLK1 has been summarised recently and concisely (Traustadóttir et al. 2019). This review has highlighted that the burden of evidence is suggestive that DLK1 has a role in inhibiting differentiation and proliferation in cells. The role for DLK1 in inhibition of differentiation is most well studied in preadipocytes. DLK1 has long been established a marker of preadipocytes, known under the alias of preadipocyte factor 1 (Smas \& Sul 1993). It is endogenously expressed in the mouse preadipocyte cell line 3T3-L1, making this a useful model for studying its function. In addition to marking this undifferentiated population, it has been shown that DLK1 actively inhibits adipocyte differentiation in cell lines. Interestingly, this effect has been shown to be attributed to the cleavable isoform of DLK1 and can be replicated with administration of the cleaved ligand (Mei et al. 2002). In this model, the membrane-bound isoform of DLK1 does not inhibit differentiation. Mechanistically, it has been shown that the interaction between the juxtamembrane domain of DLK1 with fibronectin is necessary for DLK1-mediated inhibition of adipocyte differentiation, via activation of mitogen-activated protein kinase (MAPK)/extracellular signal-regulated kinase (ERK) signalling pathway and the subsequent upregulation of SRY-Box Transcription Factor 9 (Sox9) (Wang et al. 2010).

However, the membrane-bound form of DLK1 does also have a role in regulating adipogenesis. It has been shown that the membrane-bound form of DLK1 (but not the soluble form) prevents proliferation of preadipocytes (Mortensen etal.2012). This effect occurs through inhibition of G1 to $\mathrm{S}$ phase cell-cycle progression. These findings are corroborated in a mouse model of rhabdosarcoma where soluble DLK1 inhibits and membrane-bound DLK1 increases myotubule formation (Jørgensen et al. 2013). These experiments are suggestive of a dual functional role 
of the spliced isoforms of DLK1 in both physiology and disease, and this is backed up by studies in other tissues.

Expression data implicate a role for DLK1 in myogenesis. It has been shown that the different isoforms of DLK1 exact different roles in this process. Using the mouse myoblast cell line $\mathrm{C} 2 \mathrm{C} 12$, an American group has shown the soluble DLK1 inhibits myogenic differentiation and myotubule formation whereas the membrane-bound DLK1 promotes myotubule formation (Shin et al. 2014). These findings are somewhat discrepant from the role of membrane-bound DLK1 in adipocytes and what has been described more generally that DLK1 is an inhibitor of proliferation (Mortensen et al. 2012, Traustadóttir et al. 2019). C2C12 cells do not express endogenous DLK1; however, the suggestion that this model may not be useful in determining functional data for DLK1 in vivo can be countered by what we know from callipyge sheep. Callipyge sheep exhibit a phenotype of pelvic limb, loin and shoulder muscle hypertrophy from a young age. It has been established that the cause of this condition is a point mutation within the intergenic region of DLK1/MEG3 of the paternal allele leading to increased DLK1 expression (Charlier et al. 2001). This phenotype of unphysiological muscle hypertrophy fits with the data that DLK1 has a role in myotubule proliferation and highlights the complexity of the genetic regulation of DLK1 expression. It is plausible that DLK1 isoforms have certain functional roles that are tissue-specific in this regard; however, the weight of evidence suggests that DLK1 has a crucial role in the balance of cellular differentiation and proliferation, and that is how it exacts its influence in growth, development and disease.

More recently another study has identified different roles for the DLK1 isoforms in cells derived from mouse embryonic liver (Huang et al. 2019b). This group sorted cells from hepatic spheroid-derived cells to be DLK1 positive and negative. Interestingly, when they interrogated the transcriptome and later the protein expression within these groups, the sorting had differentiated the groups based on expression of the membrane-bound DLK1 isoform whereas the soluble form was expressed in both groups. They found that presence of the membranebound DLK1 isoform was associated with more markers of stemness allowing the bi-potential differentiation for the hepatic progenitor cells to become either hepatocytes or cholangiocytes. These features were not found in the DLK1 negative population that did not contain the membranebound form. In this study, proliferation ability was not different between the two populations. Forced expression of the membrane-bound DLK1 in the population lacking it seemed to restore the bi-potential ability of these cells, and this was associated with inactivation of NOTCH and Aktkinase and activation of MAPK/ERK signalling.

The different cell type effects are also highlighted in vivo through transgenic mice models. Dlk1 knock out mice exhibit a phenotype of retarded growth, obesity, blepharophimosis, skeletal malformation, and increased serum lipid metabolites (Moon et al. 2002). The altered fat tissue dynamics are likely explained by earlier terminal differentiation and disinhibition of proliferation. In other tissue types such as muscle, where DLK1 has been shown to increase proliferation, its absence has a clearer effect with growth retardation and congenital abnormalities of disordered growth. Interestingly, maternal uniparental disomy of chromosome 12 in mice leads to a very similar phenotype but is lethal perinatally suggestive that other paternal imprinted genes from the locus may be crucial to life or indeed that maternal transcripts may increase the severity of a DLK1 knock out phenotype. Paternal uniparental disomy at this locus is lethal in utero and is associated with increased myotubule formation and ossification abnormalities (Georgiades et al. 2000).

More can be learned about specific $D L K 1$ dose increases in vivo. Transgenic mice generated to have either a double or triple dose of DLK1 exhibit a dose-dependent early growth advantage in utero (Teixeira da Rocha et al. 2009). This however is associated with failure to thrive later and is associated with an increased frequency of embryonic mortality. This is to suggest further that the function of DLK1 in physiology is to regulate the fine balance between proliferation and differentiation in developing tissue.

\section{Evidence from human genetic conditions}

Further knowledge of DLK1 function in physiology can be derived from human genetic conditions. Temple syndrome is a rare condition caused by uniparental disomy of maternal chromosome $14 \mathrm{q} 32$. This leads to the sufferer inheriting two imprinted maternal copies of $D L K 1$ along with other paternally expressed genes at this locus and double doses of maternally expressed genes. The clinical phenotype is like what is seen in the mouse although is not lethal as maternal uniparental disomy of chromosome 12 is in mice. Sufferers have lower birth weight and growth retardation. It is also associated with increased incidence of obesity, diabetes mellitus and central precocious puberty (Enterina et al. 2017). It is likely a lot of these consequences are because of low DLK1 levels. This has been shown by investigation into cohorts of patients with central precocious puberty where loss of function DLK1 mutations have been identified as likely genetic causes. These patients 
present with a similar phenotype to Temple syndrome with insulin resistance, dysregulated lipids and increased adiposity and weight (Gomes et al. 2019). This evidence is compelling for the established functional role of DLK1 in human physiology and highlights that the mice models used are appropriate surrogates for investigation.

\section{Evidence from cell lines}

There is also good evidence for the function role of DLK1 from experiments in cancer cell lines. DLK1 levels are known to be elevated in higher grade ovarian cell lines. When overexpressed in these models, DLK1 leads to increased proliferation, angiogenesis and EMT (Huang et al. 2019a). These oncogenic behaviours are an effect of the cleaved DLK1 ligand causing activation of the NOTCH 1 receptor. Taken together with the experiment in hepatic spheroid-derived cells, this is suggestive of how DLK1 exacts its function is at least partly mediated through NOTCH signalling, and the different isoforms may exact opposite effects on this pathway (Huang et al. 2019a,b).

The true relationship of how DLK1 interacts with NOTCH signalling is not clear with numerous conflicting reports from different models as to whether it can activate, inhibit or not affect NOTCH signalling (Traustadóttir et al. 2019). It is possible that the key to understanding the relationship of this interaction comes from more closely interrogating the interaction of the different isoforms of DLK1 expressed by cells. This has been looked at closely in melanoma cells, SK-MEL2 (Nueda et al. 2014). These cells do not express DLK1 endogenously but overexpression of DLK1 in these cells leads to increased cell proliferation in vitro and increased tumour size formation in vivo when injected into nude mice. These effects were associated with decreased NOTCH 1 activation. When WT melanoma cells were treated with medium containing the cleaved DLK1 ligand, a similar effect was seen. There was further increased NOTCH activation when the DLK1 overexpressing cells were treated with the exogenous ligand but rather than potentiating cell growth and proliferation, it caused a decrease in cell growth. This is suggestive that the DLK1 ligand is a potent inhibitor of NOTCH1 activation in this model. This occurs in a dosedependent manner causing increased cell proliferation up to a point where it is likely the levels of NOTCH inactivation are not compatible with cell survival and further growth. The same group has also shown this same effect in the aggressive breast cancer cell line, MDA-MB-231, which showed that in addition to NOTCH, DLK1 inhibits ERK1/2 MAPK signalling in a dose-dependent manner (Nueda et al. 2017). These consequences of DLK1 toxicity are consistent with the picture seen in mice expressing triple dose of DLK1 which is not compatible with life (Teixeira da Rocha et al. 2009).

Contrary to the findings above, other models of cancer seem to support an anti-oncogenic role for soluble DLK1. In pancreatic cancer cells MIA PaCa-2, treatment with soluble DLK1 ligand both in medium and constitutively expressed led to a decrease in cell growth, migration and tumour forming ability in vivo (Lee et al. 2016). It is possible that the doses of DLK1 administered were sufficiently high to cause inability of cell proliferation or that DLK1 exerts a different effect in this model. It should be noted that none of the melanoma, breast or pancreatic cancer cell lines mentioned above endogenously produce DLK1 and therefore the effect of exogenous or overexpressed DLK1 in these models may not be wholly representative of what occurs in malignancies that express DLK1.

Although there is substantial evidence from both expression and functional data that DLK1 has a role in numerous malignancies, it is not clear what causes the upregulation of DLK1 and the reversion to a stem phenotype in these cancers. There is some evidence in neuroblastoma cells that DLK1 expression may be induced by tissue hypoxia (Kim et al. 2009). In neuroblastoma cell lines that express DLK1 endogenously, DLK1 was upregulated in conditions of hypoxia. This upregulation was induced by the action of hypoxia-inducible factor (HIF) $1 \alpha$ and $2 \alpha$. DLK1 expression in the model was associated with an increase in markers of stem cells, inhibited differentiation and promoted clonogenicity. Overexpression of DLK1 also increased tumour size formation in vivo. Interestingly, this study also showed that the cytoplasmic domain of DLK1 is important for some of these features, namely hypoxia-induced clonogenicity and tumour formation. These experiments specifically address the role of the cytoplasmic component of the full length cleavable DLK1 isoform but did not assess DLK1 cleavage in this role. It is enticing to speculate that that the 50 amino acid cytoplasmic domain of DLK1 may have a distinct function role to the cleaved ligand. The same group has gone on to show that the cytoplasmic domain of full length DLK1 is also required to inhibit differentiation of neuroblastoma cells in vitro and in vivo and that this is at least partly mediated through inhibition of ERK phosphorylation (Begum et al. 2012). They also identified that DLK1 expression is seen in hypoxic areas of tumours which is interesting as a possible explanation for the heterogenous expression seen in some cancers.

Hypoxia-induced DLK1 expression has been studied further in a murine model of glioblastoma (Grassi et al. 2020). In this model, DLK1 was seen to be overexpressed in tumours compared to adjacent brain and was also seen in areas of https://erc.bioscientifica.com

https://doi.org/10.1530/ERC-21-0208 (c) 2021 Society for Endocrinology Published by Bioscientifica Ltd. Printed in Great Britain 
hypoxia in the tumours. Using glioblastoma cultures, it was shown that hypoxia caused the ADAM17-mediated cleavage of DLK1, and this causes the cytoplasmic component to travel to the nucleus. In this model, DLK1 expression and induction also resulted in increased stemness, colony formation and invasiveness. These functions were shown to be dependent on the cleavage of DLK1 ligand causing the cytoplasmic fragment to travel to the nucleus. In this model, NOTCH activation, as assessed by a luciferase reporter assay, was shown to be unaffected by DLK1. However, hypoxiainduced DLK1 expression and cleavage led to induction of Akt pathway and suppression of p53. This further suggests that when assessing the function of DLK1, there may be different roles for the cleaved ligand, the cytoplasmic component after cleavage and for the membrane-bound isoform.

\section{Discussion}

As can be seen from the studies reviewed in this article, it is difficult to draw a definite conclusion about the exact function of DLK1. The most convincing consensus is that DLK1 is an inhibitor of differentiation both in physiology and in cancer (Table 2). This predominantly appears to be an effect of the soluble full-length isoform of DLK1.

Studies looking specifically at the membrane-bound isoform of DLK1 tend to be focussed in the development of muscle and fat tissue (Mortensen et al. 2012, Shin et al. 2014). In these tissue settings, this isoform appears to have opposite roles, causing increased tissue proliferation in muscle and inhibiting proliferation of adipose tissue. It is informative that myotubule proliferation is seen as a function of membrane-bound DLK1 expression in sarcomatous cancer models suggestive that this tissue-specific function is the same in both physiology and disease (Jørgensen et al. 2013).

There are numerous studies with conflicting reports as to the effect of full length DLK1 on proliferation, and it is hard to draw any concrete conclusions (Table 2). Not all these studies have been able to specifically strip out whether the described effects of proliferation are a direct result of the action of the DLK1 ligand and whether co-expression of the membrane-bound isoform is significant in determining its function. Additionally, it is fascinating that cleavage of soluble DLK1 not only results in secretion of a bioactive ligand but also results in nuclear translocation of the cytoplasmic portion which is essential in enhancing prooncogenic properties in some cancer models (Kim et al. 2009, Begum et al. 2012, Grassi et al. 2020). It seems highly likely that the membrane-bound and full-length isoforms of DLK1 play different functional roles which may differ in different tissue types and their ratio of expression may determine this.

\section{DLK1 and Notch signalling}

Given its structural similarities to a Notch ligand, it is unsurprising that DLK1 has a role in Notch signalling. The evidence for the nature of the effect of DLK1 on Notch signalling is also conflicting. It has been established that the DLK1-NOTCH1 interaction involves the EGF domains 5 and 6 of DLK1 and 10-15 of NOTCH1 (Traustadóttir et al. 2016). Given the structural similarity of DLK1 to a canonical Notch ligand, it is enticing to speculate that DLK1 may exhibit similar properties of cis-inhibition and trans-activation. NOTCH 1 EGF domains 11 and 12 are known to mediate transactivation in canonical signalling and therefore are the same domains that DLK1 is proposed to interact with (de Celis \& Bray 2000). This dual model of cis-inhibition and trans-activation may explain some of the conflicting interactions of DLK1 with NOTCH.

In addition to affecting Notch signalling, DLK1 exacts some of its function through separate signalling pathways. In some models, it has been shown that DLK1 has no effect on NOTCH activation, and there is conflicting evidence for both activation and inactivation of Akt and MAPK/ ERK signalling (Table 2). These pathways along with Notch signalling are important in cellular differentiation and proliferation. Finally, DLK1 has been shown to interact with itself. This is mediated through EGF domains 4 and 5 of DLK1 (Traustadóttir et al. 2017). It has been speculated that DLK1-DLK1 interaction may directly influence DLK1NOTCH1 interaction, and this could explain some of the tissue- and context-specific effects of DLK1 on Notch signalling that are described above (Traustadóttir et al. 2019). Given the inevitable role of membrane-bound DLK1 in DLK1-DLK1 interaction, it has been suggested that DLK1DLK1 interaction is how the ratio of membrane-bound to soluble DLK1 expression may influence the functional effect of DLK1 in different settings (Traustadóttir et al. 2019).

The functional role DLK1 plays in both physiology and cancer is in regulating the processes of tissue differentiation and proliferation. These processes are not entirely dependent on DLK1 as DLK1 knock-out mice are viable, but the role of DLK1 in somatic growth and tissue regeneration is essential for good health and normal physiology. In addition to the function that DLK1 can exert on many different tissues, it does appear to be a bona fide marker of undifferentiated/progenitor cells and is recognised as a stem cell marker in certain tissues. The re-expression and upregulation of DLK1 in cancer seems to signify a 
Table 2 The functional effect of DLK1.

\begin{tabular}{|c|c|c|c|c|c|}
\hline Cell type & Paper & Isoform & Proliferation & $\overline{\text { Differentiation }}$ & Pathway action \\
\hline Mouse preadipocyte cells & (Mei et al. 2002) & DLK1 FL & & Inhibitor & \\
\hline Mouse preadipocyte cells & $\begin{array}{l}\text { (Mortensen } \\
\text { et al. 2012) }\end{array}$ & DLK1 FL & No effect & & \\
\hline Mouse rhabdosarcoma cells & $\begin{array}{l}\text { (Jørgensen } \\
\text { et al. 2013) }\end{array}$ & DLK1 FL & Inhibitor & & \\
\hline Mouse myoblast cells & (Shin et al. 2014) & DLK1 FL & Inhibitor & Inhibitor & \\
\hline Mouse embryonic hepatic cells & (Huang et al. 2019b) & DLK1 FL & No effect & No effect & \\
\hline Human ovarian carcinoma cells & (Huang et al. 2019a) & DLK1 FL & Enhancer & EMT & NOTCH activation \\
\hline Human melanoma cells & (Nueda et al. 2014) & DLK1 FL & Enhancer* & & $\begin{array}{l}\text { NOTCH } \\
\text { inactivation }\end{array}$ \\
\hline Human breast cancer cells & (Nueda et al. 2017) & DLK1 FL & Enhancer* & & $\begin{array}{l}\mathrm{NOTCH} \\
\text { inactivation } \\
\text { MAPK inactivation }\end{array}$ \\
\hline Human pancreatic cancer cells & (Lee et al. 2016) & DLK1 FL & Inhibitor & & \\
\hline Human neuroblastoma cells & (Kim et al. 2009) & $\begin{array}{l}\text { DLK1 FL } \\
\text { (cytoplasmic portion) }\end{array}$ & Enhancer & Inhibitor & \\
\hline Human neuroblastoma cells & (Begum et al. 2012) & $\begin{array}{l}\text { DLK1 FL } \\
\text { (cytoplasmic portion) }\end{array}$ & & Inhibitor & ERK inactivation \\
\hline Mouse glioblastoma cells & (Grassi et al. 2020) & $\begin{array}{l}\text { DLK1 FL } \\
\text { (cytoplasmic portion) }\end{array}$ & Enhancer & Inhibitor & $\begin{array}{l}\text { Akt activation } \\
\text { p53 suppression }\end{array}$ \\
\hline Mouse preadipocyte cells & $\begin{array}{l}\text { (Mortensen } \\
\text { et al. 2012) }\end{array}$ & DLK1 MB & Inhibitor & & \\
\hline Mouse rhabdosarcoma cells & (Jørgensen et al. 2013) & DLK1 MB & Enhancer & & \\
\hline Mouse myoblast cells & (Shin et al. 2014) & DLK1 MB & Enhancer & & \\
\hline Mouse embryonic hepatic cells & (Huang et al. 2019b) & DLK1 MB & No effect & Inhibitor & $\begin{array}{l}\text { NOTCH } \\
\text { inactivation } \\
\text { Akt inactivation } \\
\text { MAPK/ERK } \\
\text { activation }\end{array}$ \\
\hline
\end{tabular}

reversion to a less differentiated phenotype. It is plausible that in malignancy, DLK1 expression marks a population of cancer stem cells/transient amplifying cells, and it is the innate therapeutic resistance of these populations that confers the negative prognostic connotations of DLK1 expression in many cancers (Table 1 ).

\section{DLK1 as a biomarker}

As DLK1 expression is restricted to a few subpopulations of mainly (neuro)endocrine cells, its upregulated expression in malignancy makes it an attractive candidate as both a biomarker and possibly a therapeutic target. It is possible to detect the circulating DLK1 ligand in human serum and plasma samples. In health, DLK1 serum levels are usually very low and close to undetectable. This changes in pregnancy where mothers have much higher measureable levels of DLK1, and this has been shown to originate from the growing foetus (Cleaton et al. 2016). Several studies have shown that DLK1 levels are measurable in blood in cancers that are known to express DLK1. In humans, this research has been restricted to hepatoblastoma and hepatocellular carcinoma thus far. However, in both of these models, it does show potential as a novel biomarker especially as DLK1 levels are detectable in some cases where AFP, an established biomarker of liver malignancy, is negative (Falix et al. 2012, Li et al. 2015). Recently, it has been shown that serum DLK1 levels correlate with tumour size in murine ovarian cancer (Huang et al. 2019a). The higher expression of DLK1 in certain endocrine related cancers makes it an attractive prospect for further research as a biomarker in these settings.

\section{DLK1 as a potential therapeutic target}

To date, there are few data regarding experimental therapeutic approaches targeting DLK1. One approach has used a vaccine against DLK1 in a mouse model of renal cell carcinoma (Chi Sabins et al. 2013). This is an interesting study as it showed contrary to the report of (c) 2021 Society for Endocrinology Published by Bioscientifica Ltd. Printed in Great Britain 

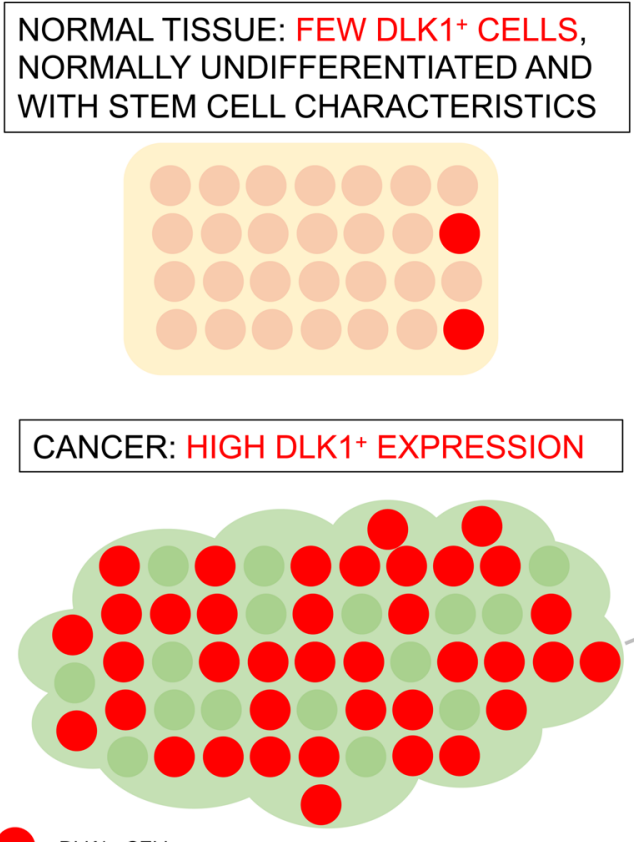

$=\mathrm{DLK} 1+\mathrm{CELL}$

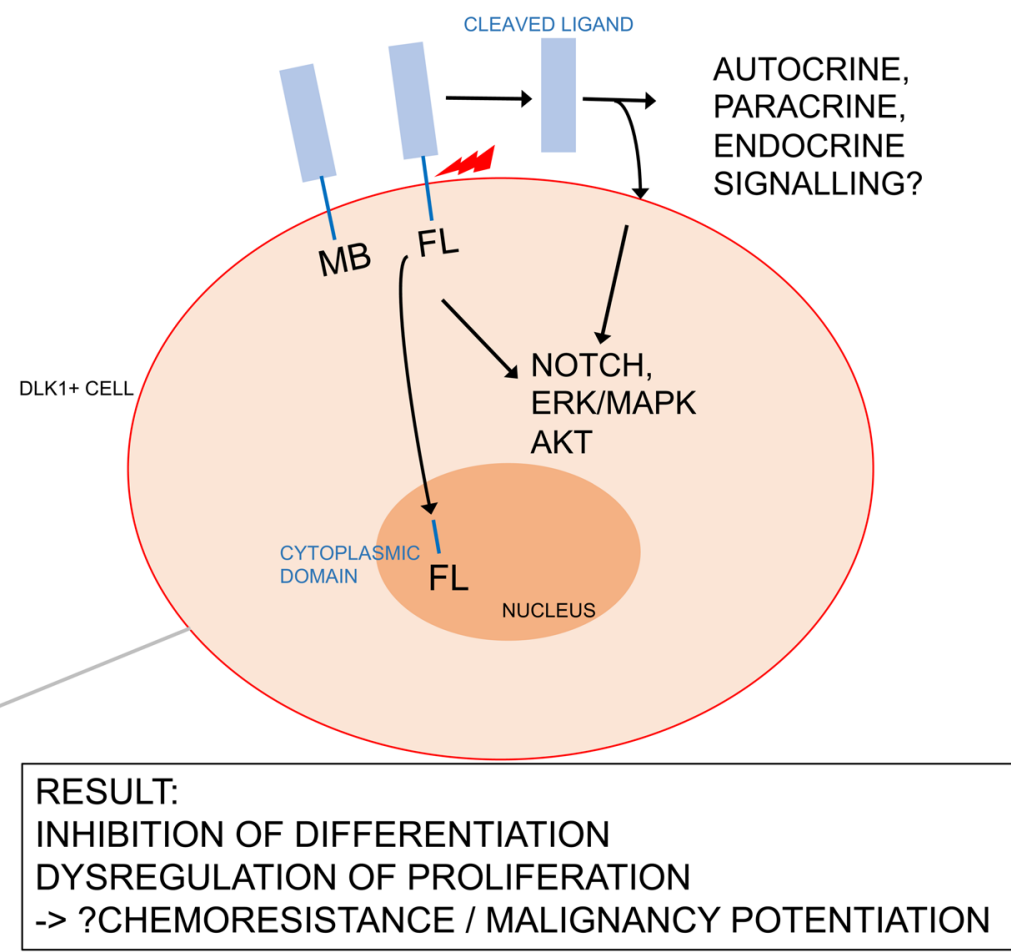

\section{Figure 3}

The role of DLK1 in cancer. Diagram illustrating the higher expression of DLK1 + cells in cancer, the two isoforms and the pathways they are shown to interact with. The possible modes of signalling of DLK1 are detailed as is a hypothesis as to how DLK1 exacts its oncogenic effects. FL, full length DLK1 isoform; MB, membrane-bound isoform. A full colour version of this figure is available at https://doi.org/10.1530/ERC-21-0208.

DLK1 having an anti-oncogenic role in RCC (Kawakami et al. 2006). They found that DLK1 was overexpressed in tumoral pericytes and caused increased tumour growth, decreased apoptosis and a less inflammatory tumour environment. A vaccine, raised in interleukin 12 modified dendritic vells pulsed with major histocompatibility complex class I-presented DLK1, was able to mediate these effects. It resulted in smaller tumours, higher interferon gamma levels and a pro-inflammatory tumour microenvironment.

More recently, the application of an anti-DLK1 antibody bound to radioactive iodine 125 has been used in a mouse lung cancer model (Takagi et al. 2021). They showed that the radioactive antibody was taken up into tumour cells, but that there was also a significant take up in other healthy tissue sites, most notably in blood. These novel experimental therapeutic approaches have both proven proof of concept, and it is possible that, with refinement, targeted therapeutic approaches to DLK1 in cancer may prove to be translatable to clinical medicine. Additionally, some simpler therapies may influence DLK1 signalling as it has been shown that beta carotene causes down regulation of DLK1 mRNA in neuroblastoma cells (Kim et al. 2016).

\section{Conclusion}

The expression and functional data reported above are suggestive of a role for DLK1 in the maintenance and malignancy of certain cancers. Although best established in common solid tumours such as liver, brain and lung, this is becomingly increasingly recognised in endocrinerelated cancers where generally expression is seen at higher levels (Table 1).

Taking the evidence reviewed here together, it would appear that the best consensus statement on the role of DLK1 in cancer is that it inhibits differentiation and dysregulates proliferation. As a result, we speculate that DLK1 may be important in driving chemoresistance and potentiating malignancy in cancers (Fig. 3). DLK1 is a promising molecule for further investigation as a biomarker in these cancers and may even prove to be a potential therapeutic target.

\section{Declaration of interest}

The authors declare that there is no conflict of interest that could be perceived as prejudicing the impartiality of this review.

\section{Funding}

This work was supported by the Medical Research Council (grant number MR/S022155/1 to J P) and the Barts Charity (grant number MGU0436 to L G). 


\section{References}

Abdallah BM, Jensen CH, Gutierrez G, Leslie RGQ, Jensen TG \& Kassem M 2004 Regulation of human skeletal stem cells differentiation by Dlk1/ Pref-1. Journal of Bone and Mineral Research 19 841-852. (https://doi. org/10.1359/JBMR.040118)

Altenberger T, Bilban M, Auer M, Knosp E, Wolfsberger S, Gartner W, Mineva I, Zielinski C, Wagner L \& Luger A 2006 Identification of DLK1 variants in pituitary- and neuroendocrine tumors. Biochemical and Biophysical Research Communications 340 995-1005. (https://doi. org/10.1016/j.bbrc.2005.12.094)

Andersen DC, Petersson SJ, Jørgensen LH, Bollen P, Jensen PB, Teisner B, Schroeder HD \& Jensen CH 2009 Characterization of DLK1+ cells emerging during skeletal muscle remodeling in response to myositis, myopathies, and acute injury. Stem Cells 27 898-908. (https://doi. org/10.1634/stemcells.2008-0826)

Araujo AN, Camacho CP, Mendes TB, Lindsey SC, Moraes L, Miyazawa M, Delcelo R, Pellegrino R, Mazzotti DR, Maciel RMB, et al. 2021 Comprehensive assessment of copy number alterations uncovers recurrent AIFM3 and DLK1 copy gain in medullary thyroid carcinoma. Cancers 13 218. (https://doi.org/10.3390/cancers13020218)

Bachmann E, Krogh TN, Højrup P, Skjødt K \& Teisner B 1996 Mouse fetal antigen 1 (mFA1), the circulating gene product of mdlk, pref- 1 and SCP-1: isolation, characterization and biology. Journal of Reproduction and Fertility 107 279-285. (https://doi.org/10.1530/jrf.0.1070279)

Begum A, Kim Y, Lin Q \& Yun Z 2012 DLK1, delta-like 1 homolog (Drosophila), regulates tumor cell differentiation in vivo. Cancer Letters 318 26-33. (https://doi.org/10.1016/j.canlet.2011.11.032)

Carrillo-Reixach J, Torrens L, Simon-Coma M, Royo L, Domingo-Sàbat M, Abril-Fornaguera J, Akers N, Sala M, Ragull S, Arnal M, et al. 2020 Epigenetic footprint enables molecular risk stratification of hepatoblastoma with clinical implications. Journal of Hepatology $\mathbf{7 3}$ 328-341. (https://doi.org/10.1016/j.jhep.2020.03.025)

Ceder JA, Jansson L, Helczynski L \& Abrahamsson PA 2008 Delta-like 1 (Dlk-1), a novel marker of prostate basal and candidate epithelial stem cells, is downregulated by Notch signalling in intermediate/transit amplifying cells of the human prostate. European Urology $\mathbf{5 4}$ 1344-1353. (https://doi.org/10.1016/j.eururo.2008.03.006)

Charlier C, Segers K, Karim L, Shay T, Gyapay G, Cockett N \& Georges M 2001 The callipyge mutation enhances the expression of coregulated imprinted genes in cis without affecting their imprinting status. Nature Genetics 27 367-369. (https://doi.org/10.1038/86856)

Cheunsuchon P, Zhou Y, Zhang X, Lee H, Chen W, Nakayama Y, Rice KA, Tessa Hedley-Whyte E, Swearingen B \& Klibanski A 2011 Silencing of the imprinted DLK1-MEG3 locus in human clinically nonfunctioning pituitary adenomas. American Journal of Pathology 179 2120-2130. (https://doi.org/10.1016/J.AJPATH.2011.07.002)

Chi Sabins N, Taylor JL, Fabian KP, Appleman LJ, Maranchie JK, Stolz DB \& Storkus WJ 2013 DLK1: a novel target for immunotherapeutic remodeling of the tumor blood vasculature. Molecular Therapy 21 1958-1968. (https://doi.org/10.1038/mt.2013.133)

Cleaton MAM, Dent CL, Howard M, Corish JA, Gutteridge I, Sovio U, Gaccioli F, Takahashi N, Bauer SR, Charnock-Jones DS, et al. 2016 Fetus-derived DLK1 is required for maternal metabolic adaptations to pregnancy and is associated with fetal growth restriction. Nature Genetics 48 1473-1480. (https://doi.org/10.1038/ng.3699)

Cordle J, Johnson S, Zi Yan Tay J, Roversi P, Wilkin MB, De Madrid BH, Shimizu H, Jensen S, Whiteman P, Jin B, et al. 2008 A conserved face of the Jagged/Serrate DSL domain is involved in Notch trans-activation and cis-inhibition. Nature Structural and Molecular Biology 15 849-857. (https://doi.org/10.1038/nsmb.1457)

de Celis JF \& Bray SJ 2000 The Abruptex domain of Notch regulates negative interactions between Notch, its ligands and Fringe. Development 127 1291-1302. (https://doi.org/10.1242/dev.127.6.1291) Dezső K, Halász J, Bisgaard HC, Paku S, Turányi E, Schaff Z \& Nagy P 2008 Delta-like protein (DLK) is a novel immunohistochemical marker for human hepatoblastomas. Virchows Archiv 452 443-448. (https://doi. org/10.1007/s00428-007-0571-8)

Enterina JR, Enfield KSS, Anderson C, Marshall EA, Ng KW \& Lam WL 2017 DLK1-DIO3 imprinted locus deregulation in development, respiratory disease, and cancer. Expert Review of Respiratory Medicine 11 749-761. (https://doi.org/10.1080/17476348.2017.1355241)

Falix FA, Aronson DC, Lamers WH, Hiralall JK \& Seppen J 2012 DLK1, a serum marker for hepatoblastoma in young infants. Pediatric Blood and Cancer 59 743-745. (https://doi.org/10.1002/pbc.24024)

Fay TN, Jacobs I, Teisner B, Poulsen O, Chapman MG, Stabile I, Bohn H, Westergaard JG \& Grudzinskas JG 1988 Two fetal antigens (FA-1 and FA-2) and endometrial proteins (PP12 and PP14) isolated from amniotic fluid; preliminary observations in fetal and maternal tissues. European Journal of Obstetrics, Gynecology, and Reproductive Biology 29 73-85. (https://doi.org/10.1016/0028-2243(88)90167-0)

Floridon C, Jensen CH, Thorsen P, Nielsen O, Sunde L, Westergaard JG, Thomsen SG \& Teisner B 2000 Does fetal antigen 1 (FA1) identify cells with regenerative, endocrine and neuroendocrine potentials? A study of FA1 in embryonic, fetal, and placental tissue and in maternal circulation. Differentiation: Research in Biological Diversity 66 49-59. (https://doi.org/10.1046/j.1432-0436.2000.066001049.x)

Fukuzawa R, Heathcott RW, Morison IM \& Reeve AE 2005 Imprinting, expression, and localisation of DLK1 in Wilms tumours. Journal of Clinical Pathology 58 145-150. (https://doi.org/10.1136/ jcp.2004.021717)

Georgiades P, Watkins M, Surani MA \& Ferguson-Smith AC 2000 Parental origin-specific developmental defects in mice with uniparental disomy for chromosome 12. Development 127 4719-4728. (https://doi. org/10.1242/dev.127.21.4719)

Gomes LG, Cunha-Silva M, Crespo RP, Ramos CO, Montenegro LR, Canton A, Lees M, Spoudeas H, Dauber A, Macedo DB, et al. 2019 Dlk1 is a novel link between reproduction and metabolism. Journal of Clinical Endocrinology and Metabolism 104 2112-2120. (https://doi. org/10.1210/jc.2018-02010)

Grassi ES, Pantazopoulou V \& Pietras A 2020 Hypoxia-induced release, nuclear translocation, and signaling activity of a DLK1 intracellular fragment in glioma. Oncogene 39 4028-4044. (https://doi.org/10.1038/ s41388-020-1273-9)

Gubina E, Ruiz-Hidalgo MJ, Baladrón V \& Laborda J 1999 Assignment of DLK1 to human chromosome band 14q32 by in situ hybridization. Cytogenetics and Cell Genetics 84 206-207. (https://doi. org/10.1159/000015259)

Gubina E, Ruiz-Hidalgo MJ, Baladrón V \& Laborda J 2000 Assignment of dlk (Dlk1) to mouse chromosome band 12E-F1 by in situ hybridization. Cytogenetics and Cell Genetics 88 322-323. (https://doi. org/10.1159/000015519)

Hadjidemetriou I, Mariniello K, Ruiz-Babot G, Pittaway J, Mancini A, Mariannis D, Gomez-Sanchez CE, Parvanta L, Drake WM, Chung TT, et al. 2019 DLK1/PREF1 marks a novel cell population in the human adrenal cortex. Journal of Steroid Biochemistry and Molecular Biology 193 105422. (https://doi.org/10.1016/j.jsbmb.2019.105422)

Helman LJ, Thiele CJ, Marston Linehant W, Nelkint BD, Baylint SB \& Israel MA 1987 Molecular markers of neuroendocrine development and evidence of environmental regulation (CDNA cloning/differential hybridization/neuroendocrine). PNAS 84 2336-2339. (https://doi. org/10.1073/pnas.84.8.2336)

Huang J, Zhang X, Zhang M, Zhu JD De, Zhang YL, Lin Y, Wang KS, Qi XF, Zhang Q, Liu GZ, et al. 2007 Up-regulation of DLK1 as an imprinted gene could contribute to human hepatocellular carcinoma. Carcinogenesis 28 1094-1103. (https://doi.org/10.1093/carcin/bgl215)

Huang CC, Cheng SH, Wu CH, Li WY, Wang JS, Kung ML, Chu TH, Huang ST, Feng CT, Huang SC, et al. 2019a Delta-like 1 homologue promotes tumorigenesis and epithelial-mesenchymal transition of ovarian high-grade serous carcinoma through activation of Notch signaling. Oncogene 38 3201-3215. (https://doi.org/10.1038/s41388018-0658-5) (c) 2021 Society for Endocrinology Published by Bioscientifica Ltd. Printed in Great Britain 
Huang J, Zhao X, Wang J, Cheng Y, Wu Q, Wang B, Zhao F, Meng L, Zhang Y, Jin M, et al. 2019b Distinct roles of Dlk1 isoforms in bi-potential differentiation of hepatic stem cells. Stem Cell Research and Therapy 10 31. (https://doi.org/10.1186/s13287-019-1131-2)

Ikeda H, Harada K, Sato Y, Sasaki M, Yoneda N, Kitamura S, Sudo Y, Ooi A \& Nakanuma Y 2013 Clinicopathologic significance of combined hepatocellular-cholangiocarcinoma with stem cell subtype components with reference to the expression of putative stem cell markers. American Journal of Clinical Pathology 140 329-340. (https:// doi.org/10.1309/AJCP66AVBANVNTQJ)

Jensen CH, Teisner B, Højrup P, Rasmussen HB, Madsen OD, Nielsen B \& Skjødt K 1993 Studies on the isolation, structural analysis and tissue localization of fetal antigen 1 and its relation to a human adrenalspecific cDNA, PG2. Human Reproduction 8 635-641. (https://doi. org/10.1093/oxfordjournals.humrep.a138110)

Jensen CH, Krogh TN, Højrup P, Clausen PP, Skjødt K, Larsson LI, Enghild JJ \& Teisner B 1994 Protein structure of fetal antigen 1 (FA1): a novel circulating human epidermal-growth-factor-like protein expressed in neuroendocrine tumors and its relation to the gene products of Dlk and pG2. European Journal of Biochemistry 225 83-92. (https://doi.org/10.1111/j.1432-1033.1994.00083.x)

Jensen CH, Erb K, Westergaard LG, Kliem A \& Teisner B 1999 Fetal antigen 1 , an EGF multidomain protein in the sex hormone-producing cells of the gonads and the microenvironment of germ cells. Molecular Human Reproduction 5 908-913. (https://doi.org/10.1093/molehr/5.10.908)

Jensen CH, Meyer M, Schroder HD, Kliem A, Zimmer J \& Teisner B 2001 Neurons in the monoaminergic nuclei of the rat and human central nervous system express FAI/dlk. NeuroReport 12 3959-3963. (https:// doi.org/10.1097/00001756-200112210-00021)

Jin ZH, Yang RJ, Dong B \& Xing BC 2008 Progenitor gene DLK1 might be an independent prognostic factor of liver cancer. Expert Opinion on Biological Therapy 8 371-377. (https://doi.org/10.1517/14712598.8.4.371)

Jørgensen LH, Sellathurai J, Davis EE, Thedchanamoorthy T, Al-Bader RWAA, Jensen CH \& Schrøder HD 2013 Delta-like 1 homolog (Dlk1): a marker for rhabdomyosarcomas implicated in skeletal muscle regeneration. PLoS ONE 8 e60692. (https://doi.org/10.1371/journal. pone.0060692)

Kawakami T, Chano T, Minami K, Okabe H, Okada Y \& Okamoto K 2006 Imprinted DLK1 is a putative tumor suppressor gene and inactivated by epimutation at the region upstream of GTL2 in human renal cell carcinoma. Human Molecular Genetics 15 821-830. (https://doi. org/10.1093/hmg/ddl001)

Khoury H, Suarez-Saiz F, Wu S \& Minden MD 2010 An upstream insulator regulates DLK1 imprinting in AML. Blood 115 2260-2263. (https:// doi.org/10.1182/blood-2009-03-212746)

Kim Y, Lin Q, Zelterman D \& Yun Z 2009 Hypoxia-regulated delta-like 1 homologue enhances cancer cell stemness and tumorigenicity. Cancer Research 69 9271-9280. (https://doi.org/10.1158/0008-5472.CAN-091605)

Kim YS, Kim E, Park YJ \& Kim Y 2016 Retinoic acid receptor $\beta$ enhanced the anti-cancer stem cells effect of $\beta$-carotene by down-regulating expression of delta-like 1 homologue in human neuroblastoma cells. Biochemical and Biophysical Research Communications 480 254-260. (https://doi.org/10.1016/j.bbrc.2016.10.041)

Laborda J, Sausville EA, Hoffman T \& Notario V 1993 dlk, a putative mammalian homeotic gene differentially expressed in small cell lung carcinoma and neuroendocrine tumor cell line. Journal of Biological Chemistry 268 3817-3820. (https://doi.org/10.1016/0169-5002(93)90224-1)

Larsen JB, Jensen CH, Schroder HD, Teisner B, Bjerre P \& Hagen C 1996 Fetal antigen 1 and growth hormone in pituitary somatotroph cells. Lancet 347 191. (https://doi.org/10.1016/S0140-6736(96)90374-8)

Lee D, Yoon SH, Lee HJ, Jo KW, Park BC, Kim IS, Choi Y, Lim JC \& Park YW 2016 Human soluble delta-like 1 homolog exerts antitumor effects in vitro and in vivo. Biochemical and Biophysical Research Communications 475 209-215. (https://doi.org/10.1016/j. bbrc.2016.05.076)
Li H, Cui ML, Chen TY, Xie HY, Cui Y, Tu H, Chen FH, Ge C \& Li JJ 2015 Serum DLK1 is a potential prognostic biomarker in patients with hepatocellular carcinoma. Tumour Biology 36 8399-8404. (https://doi. org/10.1007/s13277-015-3607-8)

Liu Y, Tan J, Li L, Li S, Zou S, Zhang Y, Zhang X, Ling B, Han N, Guo S, et al. 2010 Study on the molecular mechanisms of dlk1 stimulated lung cancer cell proliferation. Chinese Journal of Lung Cancer $\mathbf{1 3}$ 923-927. (https://doi.org/10.3779/j.issn.1009-3419.2010.10.12)

Lottrup G, Nielsen JE, Maroun LL, Møller LMA, Yassin M, Leffers H, Skakkebæk NE \& Rajpert-De Meyts E 2014 Expression patterns of DLK1 and INSL3 identify stages of Leydig cell differentiation during normal development and in testicular pathologies, including testicular cancer and Klinefelter syndrome. Human Reproduction 29 1637-1650. (https:// doi.org/10.1093/humrep/deu124)

Luo JH, Ren B, Keryanov S, Tseng GC, Rao UNM, Monga SP, Strom S, Demetris AJ, Nalesnik M, Yu YP, et al. 2006 Transcriptomic and genomic analysis of human hepatocellular carcinomas and hepatoblastomas. Hepatology 44 1012-1024. (https://doi.org/10.1002/ hep.21328)

Ma X, Zhang Y, Yang L, Xu Z \& Xiao Z 2012 The effects of increased expression of DLK1 gene on the pathogenesis of myelodysplastic syndromes. Clinical Lymphoma, Myeloma and Leukemia 12 261-268. (https://doi.org/10.1016/j.clml.2012.03.002)

Mei B, Zhao L, Chen L \& Sul HS 2002 Only the large soluble form of preadipocyte factor- 1 (Pref-1), but not the small soluble and membrane forms, inhibits adipocyte differentiation: role of alternative splicing. Biochemical Journal 364 137-144. (https://doi.org/10.1042/ bj3640137)

Metsuyanim S, Harari-Steinberg O, Buzhor E, Omer D, Pode-Shakked N, Ben-Hur H, Halperin R, Schneider D \& Dekel B 2009 Expression of stem cell markers in the human fetal kidney. PLoS ONE 4 e6709. (https://doi.org/10.1371/journal.pone.0006709)

Molina-Pinelo S, Salinas A, Moreno-Mata N, Ferrer I, Suarez R, AndrésLeón E, Rodríguez-Paredes M, Gutekunst J, Jantus-Lewintre E, Camps C, et al. 2018 Impact of DLK1-DIO3 imprinted cluster hypomethylation in smoker patients with lung cancer. Oncotarget 9 4395-4410. (https://doi.org/10.18632/oncotarget.10611)

Moon YS, Smas CM, Lee K, Villena JA, Kim KH, Yun EJ \& Sul HS 2002 Mice lacking paternally expressed Pref-1/Dlk1 display growth retardation and accelerated adiposity. Molecular and Cellular Biology 22 5585-5592. (https://doi.org/10.1128/MCB.22.15.5585-5592.2002)

Morganstein DL, Wu P, Mane MR, Fisk NM, White R \& Parker MG 2010 Human fetal mesenchymal stem cells differentiate into brown and white adipocytes: a role for ERRalpha in human UCP1 expression. Cell Research 20 434-444. (https://doi.org/10.1038/cr.2010.11)

Mortensen SB, Jensen CH, Schneider M, Thomassen M, Kruse TA, Laborda J, Sheikh SP \& Andersen DC 2012 Membrane-tethered deltalike 1 homolog (DLK1) restricts adipose tissue size by inhibiting preadipocyte proliferation. Diabetes 61 2814-2822. (https://doi. org/10.2337/db12-0176)

Nueda ML, Naranjo AI, Baladrón V \& Laborda J 2014 The proteins DLK1 and DLK2 modulate NOTCH1-dependent proliferation and oncogenic potential of human SK-MEL-2 melanoma cells. Biochimica et Biophysica Acta 1843 2674-2684. (https://doi.org/10.1016/j. bbamcr.2014.07.015)

Nueda ML, Naranjo AI, Baladrón V \& Laborda J 2017 Different expression levels of DLK1 inversely modulate the oncogenic potential of human MDA-MB-231 breast cancer cells through inhibition of NOTCH1 signaling. FASEB Journal 31 3484-3496. (https://doi.org/10.1096/ fj.201601341RRR)

Sakajiri S, O'Kelly J, Yin D, Miller CW, Hofmann WK, Oshimi K, Shih LY, Kim KH, Sul HS, Jensen CH, et al. 2005 Dlk1 in normal and abnormal hematopoiesis. Leukemia 19 1404-1410. (https://doi.org/10.1038/sj. leu.2403832)

Sbiera I, Kircher S, Altieri B, Fassnacht M, Kroiss M \& Sbiera S 2021 Epithelial and mesenchymal markers in adrenocortical tissues: how 
mesenchymal are adrenocortical tissues? Cancers 13 1736. (https://doi. org/10.3390/CANCERS13071736)

Scherer PE, Williams S, Fogliano M, Baldini G \& Lodish HF 1995 A novel serum protein similar to $\mathrm{C} 1 \mathrm{q}$, produced exclusively in adipocytes. Journal of Biological Chemistry 270 26746-26749. (https://doi. org/10.1074/jbc.270.45.26746)

Schmelzer E 2019 Hepatic progenitors of the fetal liver: interactions with hematopoietic stem cells. Differentiation: Research in Biological Diversity 106 9-14. (https://doi.org/10.1016/j.diff.2019.02.005)

Seino S, Tsuchiya A, Watanabe Y, Kawata Y, Kojima Y, Ikarashi S, Yanai H, Nakamura K, Kumaki D, Hirano M, et al. 2018 Clinical outcome of hepatocellular carcinoma can be predicted by the expression of hepatic progenitor cell markers and serum tumour markers. Oncotarget 9 21844-21860. (https://doi.org/10.18632/oncotarget.25074)

Shin S, Suh Y, Zerby HN \& Lee K 2014 Membrane-bound delta-like 1 homolog (Dlk1) promotes while soluble Dlk1 inhibits myogenesis in C2C12 cells. FEBS Letters 588 1100-1108. (https://doi.org/10.1016/j. febslet.2014.02.027)

Smas CM \& Sul HS 1993 Pref-1, a protein containing EGF-like repeats, inhibits adipocyte differentiation. Cell 73 725-734. (https://doi. org/10.1016/0092-8674(93)90252-L)

Takagi H, Zhao S, Muto S, Yokouchi H, Nishihara H, Harada T, Yamaguchi H, Mine H, Watanabe M, Ozaki Y, et al. 2021 Delta-like 1 homolog (DLK1) as a possible therapeutic target and its application to radioimmunotherapy using 125I-labelled anti-DLK1 antibody in lung cancer models (HOT1801 and FIGHT004) Lung Cancer 153 134-142. (https://doi.org/10.1016/J.LUNGCAN.2021.01.014)

Tan J, Zhang S, Li L, Mu J, Wang Z, Zhang L, Jiang M, Li W, Yang X, Liu Y, et al. 2019 Abnormally localized DLK1 interacts with NCOR1 in nonsmall cell lung cancer cell nuclear. Bioscience Reports 39 BSR20192362. (https://doi.org/10.1042/BSR20192362)

Tanimizu N, Nishikawa M, Saito H, Tsujimura T \& Miyajima A 2003 Isolation of hepatoblasts based on the expression of Dlk/Pref-1. Journal of Cell Science 116 1775-1786. (https://doi.org/10.1242/jcs.00388)

Teixeira da Rocha ST, Charalambous M, Lin SP, Gutteridge I, Ito Y, Gray D, Dean W \& Ferguson-Smith AC 2009 Gene dosage effects of the imprinted delta-like homologue 1 (Dlk1/Pref1) in development: implications for the evolution of imprinting. PLoS Genetics 5 e1000392. (https://doi.org/10.1371/journal.pgen.1000392)

Tornehave D, Fay TN, Teisner B, Chemnitz J, Westergaard JG \& Grudzinskas JG 1989 Two fetal antigens (FA-1 and FA-2) and endometrial proteins (PP12 and PP14) isolated from amniotic fluid: localisation in the fetus and adult female genital tract. European Journal of Obstetrics, Gynecology, and Reproductive Biology 30 221-232. (https://doi.org/10.1016/0028-2243(89)90005-1)

Tornehave D, Jansen P, Teisner B, Rasmussen HB, Chemnitz J \& Moscoso G 1993 Fetal antigen 1 (FA1) in the human pancreas: cell type expression, topological and quantitative variations during development. Anatomy and Embryology 187 335-341. (https://doi. org/10.1007/BF00185891)
Tornehave D, Jensen CH, Teisner B \& Larsson L-II 1996 FA1 immunoreactivity in endocrine tumours and during development of the human fetal pancreas; negative correlation with glucagon expression. Histochemistry and Cell Biology 106 535-542. (https://doi. org/10.1007/BF02473268)

Traustadóttir GÁ, Jensen CH, Thomassen M, Beck HC, Mortensen SB, Laborda J, Baladrón V, Sheikh SP \& Andersen DC 2016 Evidence of non-canonical NOTCH signaling: delta-like 1 homolog (DLK1) directly interacts with the NOTCH1 receptor in mammals. Cellular Signalling 28 246-254. (https://doi.org/10.1016/J.CELLSIG.2016.01.003)

Traustadóttir GÁ, Jensen CH, Garcia Ramirez JJ, Beck HC, Sheikh SP \& Andersen DC 2017 The non-canonical NOTCH1 ligand delta-like 1 homolog (DLK1) self interacts in mammals. International Journal of Biological Macromolecules 97 460-467. (https://doi.org/10.1016/J. IJBIOMAC.2017.01.067)

Traustadóttir GÁ, Lagoni LV, Ankerstjerne LBS, Bisgaard HC, Jensen CH \& Andersen DC 2019 The imprinted gene delta like non-canonical Notch ligand 1 (Dlk1) is conserved in mammals, and serves a growth modulatory role during tissue development and regeneration through Notch dependent and independent mechanisms. Cytokine and Growth Factor Reviews 46 17-27. (https://doi.org/10.1016/j.cytogfr.2019.03.006)

Turányi E, Dezső K, Paku S \& Nagy P 2009 DLK is a novel immunohistochemical marker for adrenal gland tumors. Virchows Archiv 455 295-299. (https://doi.org/10.1007/s00428-009-0819-6)

Wang Y, Zhao L, Smas C \& Sul HS 2010 Pref-1 interacts with fibronectin to inhibit adipocyte differentiation. Molecular and Cellular Biology 30 3480-3492. (https://doi.org/10.1128/MCB.00057-10)

Xu J, Wang M, Zhang Z, Zhao W, Wang C, Tu L, Zhang Y \& Cao H 2016 Prognostic values of DLK1 for surgery and imatinib mesylate adjuvant therapy in gastrointestinal stromal tumors. American Journal of Cancer Research 6 2700-2712.

Yanai H, Nakamura K, Hijioka S, Kamei A, Ikari T, Ishikawa Y, Shinozaki E, Mizunuma N, Hatake K \& Miyajima A 2010 Dlk-1, a cell surface antigen on foetal hepatic stem/progenitor cells, is expressed in hepatocellular, colon, pancreas and breast carcinomas at a high frequency. Journal of Biochemistry 148 85-92. (https://doi.org/10.1093/ $\mathrm{jb} / \mathrm{mvq034)}$

Yin D, Xie D, Sakajiri S, Miller CW, Zhu H, Popoviciu ML, Said JW, Black KL \& Koeffler HP 2006 DLK1: increased expression in gliomas and associated with oncogenic activities. Oncogene 25 1852-1861. (https://doi.org/10.1038/sj.onc.1209219)

Zhang RM, Tang T, Yu HM \& Yao XD 2018 LncRNA DLX6-AS1/miR129-5p/DLK1 axis aggravates stemness of osteosarcoma through Wnt signaling. Biochemical and Biophysical Research Communications $\mathbf{5 0 7}$ 260-266. (https://doi.org/10.1016/j.bbrc.2018.11.019)

Zwierzina ME, Ejaz A, Bitsche M, Blumer MJF, Mitterberger MC, Mattesich M, Amann A, Kaiser A, Pechriggl EJ, Hörl S, et al. 2015 Characterization of DLK1(PREF1)+/CD34+ cells in vascular stroma of human white adipose tissue. Stem Cell Research 15 403-418. (https:// doi.org/10.1016/J.SCR.2015.08.004)

Received in final form 6 September 2021

Accepted 24 September 2021

Accepted Manuscript published online 24 September 2021 (c) 2021 Society for Endocrinology Published by Bioscientifica Ltd. Printed in Great Britain 